\title{
FIRST EXPERIMENTATION OF THE SPARTACUS TELETHESIS IN A CLINICAL ENVIRONMENT
}

By H. H. Kwee, Ph.D., ${ }^{1}$ M. Tramblay, M.D., ${ }^{2}$ R. Barbier, M.S., ${ }^{1}$ M. Dupeyroux, O.T., ${ }^{1}$ M. F. VinCeneux, O.T., ${ }^{2}$ P. Semoulin, M.D. ${ }^{2}$ and S. PANNIER, M.D. ${ }^{2}$

${ }^{1}$ Université Paris XII, Centre Universitaire d'Evry, 910 II Evry Cédex, France. ${ }^{2}$ Université Paris V, Hôpital Raymond Poincaré, 92380 Garches, France.

Summary. A prototype 'telethesis', a telemanipulator for high level tetraplegic and similarly disabled persons, has been developed in the French Spartacus project. The system has a modular control structure, both in the choice of transducers and in the microprocessor programmes assuring the ergonomic link with the individual user. A special training procedure has been developed and tested both in the laboratory and in the hospital.

Six tetraplegic patients have used the system in the laboratory and seven in hospital. The experience of 6 months of experimentation in the occupational therapy department with the seven patients is reported. The telethesis has been well accepted by four of them, two of whom have used it for prolonged periods of time. One case has not been adapted with great success prior to his departure, and in two others the use of the system has been rejected, largely for psychological reasons.

Key words: Tetraplegia; Telemanipulator; Upper limbs; Rehabilitation; Technical aids.

\section{Introduction}

WITH THE improvement in the rapid care of spinal cord injury patients the survival of a growing number of severely impaired tetraplegics with about average life expectency poses the problem of how to restore them to a quality of life beyond simple subsistence (Durand et al., I978). Modern technology appears to have some solutions to offer, but its application proves to be much more difficult than might be expected. The development of the powered wheelchair and adapted controls have provided a significant improvement of independence in mobility, but the assistance of upper limb function by technical means poses a far more difficult problem. Early attempts to develop sophisticated powered orthoses have encountered the problem of matching powered mechanical structures to the human body in an acceptable way, for which no satisfactory solution has been found thus far. This has led to an approach abandoning the mobilisation of the paralysed limb, in favour of the development of a tool, functionally replacing the upper limb. Recent progress in robotics has further stimulated interest in this approach, and a review of I I projects has recently been published by Leifer (I98I).

In France, within the framework of a nationwide robotics programme, the 'Institut National de Recherche d'Informatique et d'Automatique'

Presented at the twenty-first Annual Scientific Meeting of the International Medical Society of Paraplegia, Athens, Greece. October 1982. 
(INRIA) launched in 1975 the French 'Spartacus Pilot Project'. This project had as a medical objective the demonstration of the feasibility of applying robotic technology to solve some of the functional problems of tetraplegic patients. The duration of this project was limited to 5 years and some 20 research and development groups of both technical and medical disciplines throughout France have contributed to various aspects of the project. The feasibility study was successfully terminated by the end of 1980 by the development of a prototype 'telethesis', ${ }^{\star}$ the 'MAT I', a telemanipulator with microprocessor-assisted control and a variety of transducers adaptable to the patient. Since then, the studies relative to patient application and further technical developments have continued at a more modest scale at the University Paris XII (Kwee and Pannier, I98I).

At various stages of the development numerous subjects have participated in the experimentation of the system and in particular the collaboration of six tetraplegic patients has been an essential element. By the end of I98I enough progress had been made to permit the first clinical experimentation outside the laboratory and without the permanent assistance of technical personnel. Therefore, it was decided to install the system at the 'Hôpital Raymond Poincare', one of the participating clinical teams in the project. Here it has been placed in the occupational therapy department for experimentation by various patients on a voluntary basis to give a first answer to such questions as:

I. Will it actually work outside the laboratory and what are its shortcomings?

2. What are the reactions of recent tetraplegic patients when exposed to such a system?

3. What are the reactions of the hospital personnel, and how can its use be integrated in a rehabilitation programme?

4. What training programmes are adequate under the constraints of a clinical environment?

\section{The Telethesis is MAT I}

The telethesis consists of the following elements (Fig. I):

I. An articulated mechanical arm with six degrees of freedom, powered by electrical torque motors, and carrying a powered gripper at the end. The arm has been specially designed to work on a table, to reach objects stored on shelves, and to retrieve objects that have fallen on to the floor (Vertut, I978). With the extended arm it has a range of $150 \mathrm{~cm}$ over $120^{\circ}$.

2. A variety of control transducers, selectable to suit each individual patient. In particular a head movement transducer with two or three degrees of freedom has proven to be well suited for high level tetraplegic patients. For those individuals who still have some arm movement, a roller type transducer is a very convenient complement.

\footnotetext{
* For the class of telemanipulator systems for the physically handicapped which neither replace a missing limb (like a prosthesis) nor assist a paralysed limb (like an orthosis) but are instead tools not attached to the body, we have adopted the name 'telethesis'.
} 


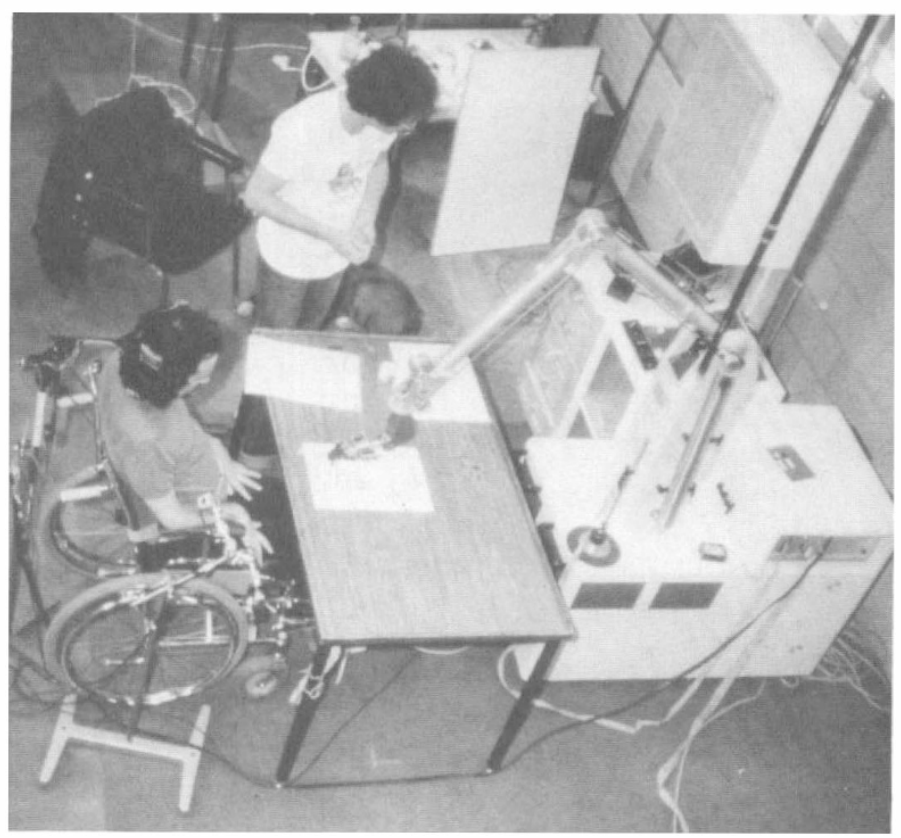

FIG. I

General view of the prototype MAT I telethesis with $M$. C. executing a figure tracking exercise.

3. A microprocessor system with special interfaces to establish an ergonomic, individually adaptable, programmable link between the user and the mechanical arm.

The control philosophy has been developed, implemented and experimented with a number of patients in the laboratory, first on a simulated system (a commercial telemanipulator for nuclear research, coupled to a mini computer) and subsequently the prototype MAT I telethesis (Guittet et al., 1979). The most critical aspect of the system consists of its manmachine interaction which must allow an operator capable of emitting only a very limited number of signals to control the seven motors of the manipulator in a coordinated way. Our goal was to restore as much as possible complete voluntary control of gripper movements, permitting the operator to perform any task not planned in advance, rather than to provide him exclusively with a limited set of pre-programmed movements or actions.

The approach adopted is a form gripper 'end point control' (Whitney, 1969), in which the operator controls only a limited number of gripping movements at the same time, while the others are held constant. Thus, the control of seven gripper movements in space (including pinching) are distributed in various combinations over a number of control 'modes', sequentially selectable by the operator to perform a complete movement. It should be noted that the movements controlled in any single mode do not need to correspond with the inherent movements of the articulations of the mechanical system. They may be specified in any coordinated system of interest to the user, with the computer taking care of calculating the corresponding joint movements. This freedom to separate joint movements 
and operator commands is one of the key factors in obtaining an ergonomic adaptation.

In the present system the basic cycle consists of four sequentiallyselectable control modes, to which other 'accessory' modes may be added. In each of these modes a maximum of three basic movements are controlled simultaneously in the following combinations:

'XYZ': control of gripper position by controlling its foreward-backward (X) left-right (Y) and up-down ( $\mathrm{Z})$ positions without modification of gripper orientation in space.

'VG': Control of gripper velocity (V), forward or backward in the direction pointed by the gripper, and of gripper opening and closing $(G)$. This combination is particularly important when releasing an object without inadvertently knocking it over.

'VJP': ('piloting'): Control of gripper velocity (V) as above, but with the possibility of changing its orientation about a vertical axis (jaw, $\mathrm{J}$ ) and about a horizontal axis (pitch, P). As a result the gripper may be 'flown as an airplane', flying forward or backward in this 'piloting' mode.

'XYR': Movements in the horizontal plane are controlled as in the $\mathrm{XYZ}$ mode, but with reduced gain for increased precision, together with gripper rotation $(\mathbf{R})$ about its longitudinal axis. This combination is necessary for such actions as pouring out a drink.

Another mode considered for implementation in the basic cycle is one of velocity control in cylindrical coordinates for long-distance displacements with a stabilised gripper, while facilitating to remain within the doughnutshaped range of accessibility of the mechanical structure. In addition, one further accessory mode has been implemented recently, facilitating drinking by simulating a natural drinking movement of tilting the glass, cup or bottle held in the gripper, while moving the gripper upwards to permit the user to tilt his head backwards and avoid hitting his nose by the ridge of the container. One single control is used to change simultaneously both rotation $R$ and vertical displacement $Z$.

The object of using a telethesis is to augment functional capabilities by using it as a tool when needed, but only then, and it should not prevent the disabled operator from using his remaining capabilities of direct control. Therefore, it is important that he is able to take control of the device, but also to uncouple it, having it remain in place and permitting him either to act directly on an object held by the gripper or perform other activities without being bothered by a moving gripper. This has been made possible by the 'clutch' function, doubling each mode in a 'coupled' and an 'uncoupled' mode.

This clutch function is also essential for a better control of movements. It establishes the link between current transducer positions (e.g. head position) and gripper position at the moment of coupling, thereby permitting the user to displace the 'zero' position to a comfortable one, to change the range of direct accessibility, and to reduce the influence of errors in transducer positioning and drift.

Clutch coupling and uncoupling as well as mode selection are controlled by one discrete signal such as a switch signal, a sound signal captured by a 
laryngophone, a myoelectric signal, etc. A short pulse switches modes from coupling to uncoupling, a maintained signal switches modes in a sequential way each time a certain preset time is exceeded. A display above the gripper informs the operator about the mode selected and the state of the clutch.

It is clear that with such a system, where the patient is within the range of the gripper or an object held by it, extensive safety measures are necessary to protect him both against operating errors and against system malfunctioning. A hierarchy of safety features, published elsewhere, have been implemented for this purpose.

\section{Operator Training}

In spite of all efforts invested to simplify the use of the telethesis, the efficient control of gripper movements in space requires the acquisition of a number of basic concepts and skills. Therefore, a systematic training programme has been developed in the laboratory (Gaillard et al., 1978) and an improved version now serves as a basis for the clinical training procedure.

The procedure consists of three phases. In the first phase the patient's collaboration is solicited as a volunteer to test a prototype instrument. The project, its goals, and its actual status are discussed, its function is explained and its operation is demonstrated. A first attempt is made to evaluate the patient's need for such an instrument to enable him to regain some independence.

The second phase starts with the selection of the transducers to be used and the elaboration of the user's individual installation, and then

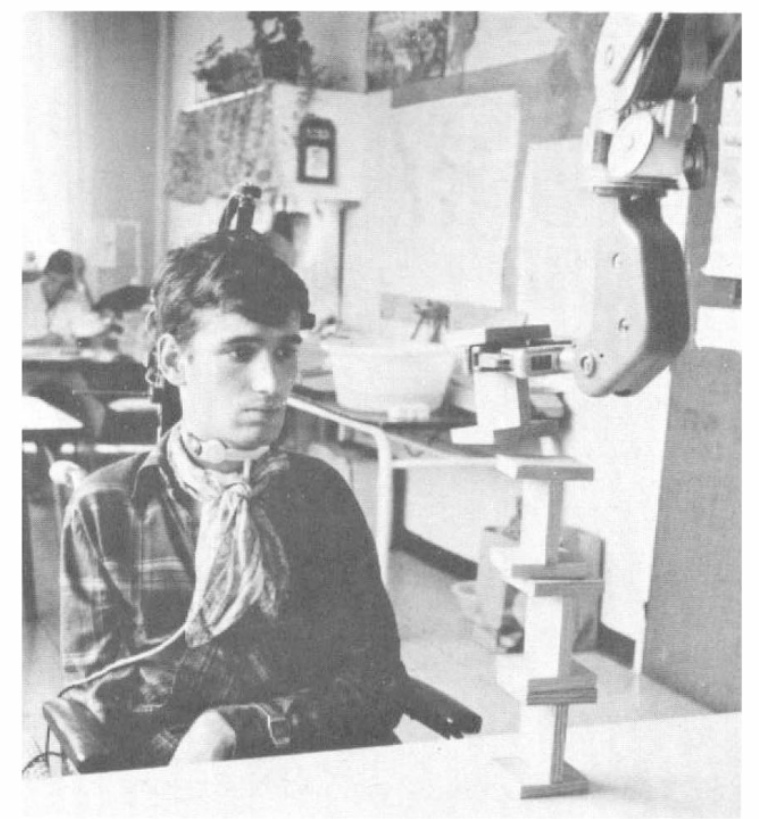

FIG. 2

C. M. using wooden ' $\mathrm{H}$-elements' in a tower-building exercise early in the training procedure. 
proceeds with the teaching of the operating principles. The basic motions and their control modes are introduced and exercised one by one, using specially designed 'H-elements' (Fig. 2) as training tools. These elements are used to construct a tower, and both their initial positions and their orientations within the tower are progressively changed in order to require increasingly complex movements to achieve the final result.

The third phase partially overlaps the second one, progressively putting into action the skills just acquired in the execution of more realistic tasks, thereby demonstrating the gain in independence obtained at each step. This demonstration is considered essential to maintain motivation and render a sense of accomplishment to the user, who is already passing through a difficult stage in his life.

This third phase continues beyond the acquisition of basic skills and has as an objective to train the operator to use the telethesis as a tool, and in a more advanced stage we solicit his participation in defining the tasks that he considers to be of importance. Among the tasks proposed in the earlier stages, and routinely included in the protocol, are pouring water from a bottle into a glass; drawing and writing, including a figure tracing task for performance evaluation (Fig. I); fetching objects from shelves (Fig. 3), dialling a number on a standard dial-type telephone; peg in hole type insertion tasks; page turning; drinking (Fig. 4) and eating. This leads to other tasks such as opening and closing cupboard doors, assembly of 'Lego elements' (large-size at first, small size later), handling a tape recorder,

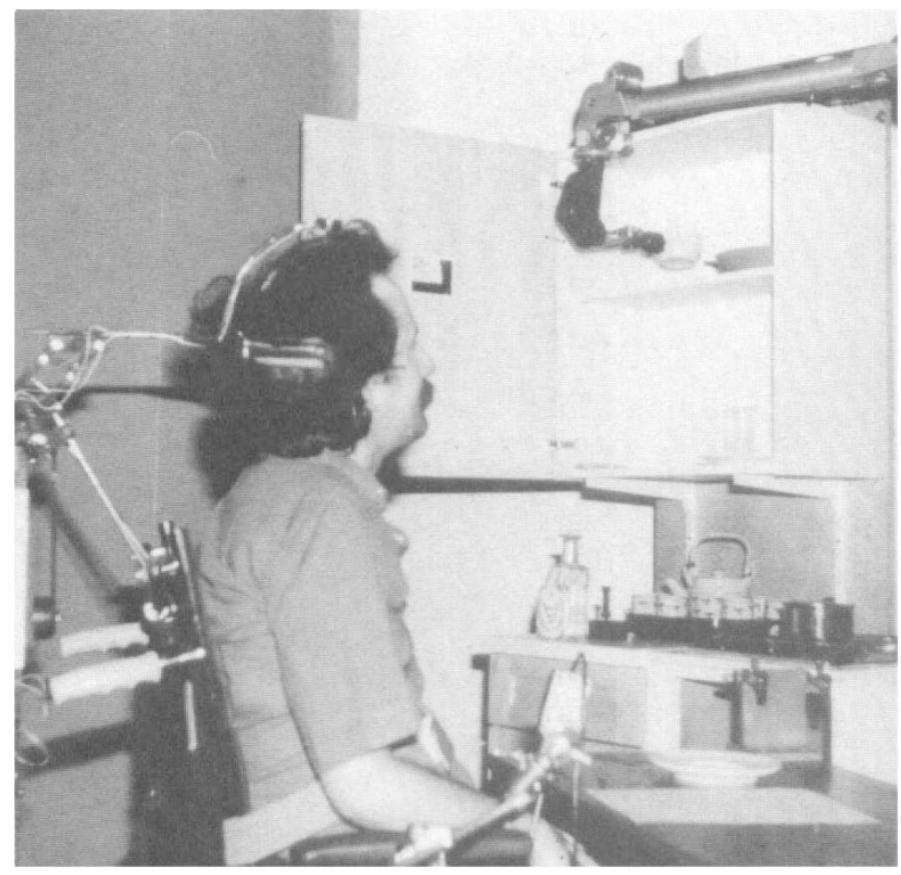

FIG 3

M. C. fetching a cup from a shelf after having opened the spring-loaded door of the cupboard. 


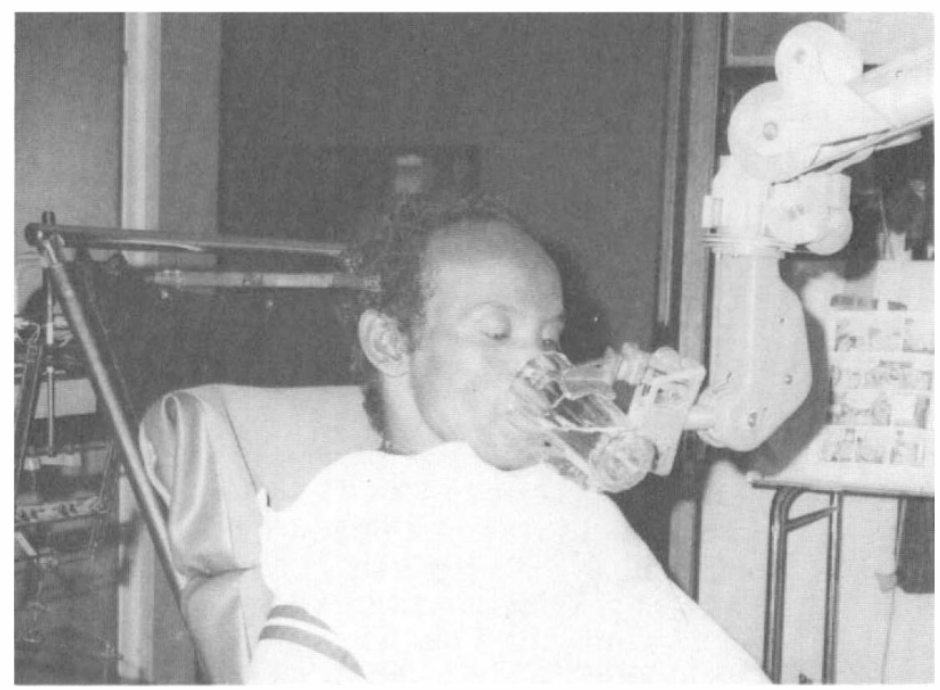

FIG. 4

G. A. drinking; the drinking movement is controlled by gross arm movements with the roller transducer.

shaving with an electric razor, using an electric knife, handling fragile objects like an egg, or a peach (and eating it), etc.

Whereas in the early stages the operator is asked to execute all tasks exclusively with the telethesis, in the later stages he is encouraged to utilise also whatever function is remaining and explore the possibilities of a 'symbiotic' operation, most suited to his personal needs.

It should be noted, that the training protocol outlined above only constitutes a skeleton, and that adaptations are required to suit both the individual patient and the instructor. In particular when working with relatively recent tetraplegic patients, still posing both acute medical and psychological problems, a great amount of flexibility is necessary.

\section{Experimental Subjects}

In the laboratory experiments six tetraplegic patients with lesions at levels between $\mathrm{C}_{3}$ and $\mathrm{C}_{4}$ have participated as volunteers at various stages of the developments. All were 'old' traumatic tetraplegic patients who had their accident between 2 and Io years previously. With the exception of the most recent one (M. C.) all of them had reorganised their lives in a stable way.

In contrast, patients participating in the first series of clinical experiments at Garches are recent tetraplegics, with the exception of two being in the first year following their accident. They still have preoccupying medical problems, and readmittance to the intensive care department is sometimes required. Psychologically, several were still severely depressed and had not yet come to terms with their condition. For the first 6 months, eight tetraplegic patients have participated in the clinical experiments on a voluntary basis for at least one hour, distributed over several sessions (Table I). 
TABLE I

Tetraplegic patients who have participated for at least I hour in the hospital

\begin{tabular}{|c|c|c|c|c|c|c|c|c|}
\hline $\begin{array}{l}\text { Subject } \\
\text { Sex }\end{array}$ & $\begin{array}{c}\text { G. A. } \\
\text { M }\end{array}$ & $\underset{M}{\text { A. T. }}$ & $\begin{array}{c}\text { C. } M \text {. } \\
M\end{array}$ & $\begin{array}{c}\text { X. M. } \\
M\end{array}$ & $\begin{array}{c}\text { G. E. } \\
M\end{array}$ & $\begin{array}{c}\text { F. S. } \\
\text { M }\end{array}$ & $\begin{array}{l}\text { J. S. } \\
\text { M }\end{array}$ & $\begin{array}{c}\text { G. Y. } \\
F\end{array}$ \\
\hline Age & 36 & 45 & 20 & I 4 & 5 & 35 & 32 & 52 \\
\hline Motor level & $\mathrm{C}_{4} / \mathrm{C}_{5}$ & $\mathrm{C}_{5} / \mathrm{C} 6$ & $\mathrm{C}_{3} / \mathrm{C}_{4}$ & $\mathrm{C}_{5} / \mathrm{C} 6$ & $\mathrm{C} 6 / \mathrm{C}_{7}$ & $\mathrm{C}_{4} / \mathrm{C}_{5}$ & $\mathrm{C}_{4} / \mathrm{C}_{5}$ & $\mathrm{C}_{4} / \mathrm{C}_{5}$ \\
\hline $\begin{array}{l}\text { Sensory level } \\
\text { Number of }\end{array}$ & $\mathrm{C}_{5}$ & $\mathrm{~T}_{4}$ & $\mathrm{C}_{4} / \mathrm{T}_{3}$ & $\mathrm{C}_{7}$ & $\mathrm{C}_{7} / \mathrm{C} 8$ & $\mathrm{C} 5 / \mathrm{C} 6$ & $\mathrm{C}_{5}$ & $\mathrm{C}_{5}$ \\
\hline $\begin{array}{l}\text { sessions } \\
\text { Estimated time }\end{array}$ & 42 & 34 & 3 & 5 & 3 & 3 & 3 & 2 \\
\hline (hours) & 24 & 22 & $5: 15$ & $2: 45$ & $2: 20$ & 2 & $1: 30$ & I \\
\hline
\end{tabular}

G. A., a 36-year-old male, unmarried. A truck driver and car mechanic. Tetraplegia resulted from a road traffic accident (Oct. 1980). Motor level: $\mathrm{C}_{4}$ incomplete, $\mathrm{C}_{5}$ complete. Sensory level: $\mathrm{C}_{5}$ complete. Slight spasticity. He has participated in 42 sessions, totalling about $\mathbf{2 4}$ hours.

A. T., a 45-year-old male, married. A mason and tile layer. Tetraplegic from an accident at work (Aug. I98I). Motor level: C4 incomplete, C6 complete. Sensory level: $\mathrm{T}_{4}$. Slight spasticity. Moderate reduction of mobility of shoulders and elbows. He has participated in 34 sessions, totalling about 22 hours. He has excellent spatial representation and has used the telethesis with great imagination. It is possible that the telethesis will serve him only as a temporary aid, as is indicated in certain people, and that in the future he will be able to cope with simpler technical aids.

C. M., a 20-year-old male, unmarried. An apprentice baker. The tetraplegia was due to a suicide attempt (gun shot, Dec. I980). Motor level: $\mathrm{C}_{3}$ incomplete, $\mathrm{C}_{4}$ complete. Sensory level: $\mathrm{C}_{4}$ incomplete $\mathrm{T}_{3}$ (right) and TI (left) complete. A pyramidal syndrome with spasticity of all four limbs, in particular of the left leg. He has participated in only three sessions, but totalling 5 hours 15 minutes, during two weeks of rehospitalisation.

$X$. M., a I4-year-old male. The tetraplegia was due to a road traffic accident (July 1970). Motor level C5 incomplete, C6 complete. Sensory level C7 complete. Has participated in five sessions, totalling 2 hours 45 minutes, interrupted by orthopaedic complications.

G.E., a 5-year-old male with postnatal tetraplegia. Motor level C6 incomplete, $\mathrm{C}_{7}$ complete. Sensory level: $\mathrm{C}_{7}$ incomplete, $\mathrm{C} 8$ complete. $\mathrm{He}$ has participated in three sessions, totalling 2 hours 20 minutes.

F. S., a 35-year-old male, married. A graduate student. Tetraplegia resulted from a road traffic accident (Sept. I98I). Motor level: $\mathrm{C}_{4}$ incomplete, C5 complete. Sensory level: C5 incomplete, C6 complete. Spastic. He has participated in only three sessions, totalling only 2 hours, because of recurring complications necessitating admission to the intensive care unit.

F. S., a 32-year-old male, married. An oil well driller. The tetraplegia resulted from a wind surfing accident (July I98I). Motor level: $\mathrm{C}_{4}$ incomplete, $\mathrm{C}_{5}$ complete. Sensory level: $\mathrm{C}_{5}$ complete. Very spastic. Depressed. Very much opposed to the telethesis at first, then agreed to participate in some experiments, but finally refused to continue because of 
his depressive state. This was followed by re-admission to the intensive care unit. He has participated in three sessions, totalling $\mathrm{I} \frac{1}{2}$ hours.

G. Y., a 52-year-old female, married. Occupation: domestic activities. Tetraplegia was due to a road traffic accident. Motor level: $\mathrm{C}_{4}$ incomplete, C5 complete. Sensory level: C5 $_{5}$ complete. She has participated in only two sessions, totalling one hour. She was very eager to return home and was not interested in learning to operate a tool that would not become available to her.

Table I summarises the sex, age, level of tetraplegia, the number of sessions, and the estimated time that each patient has participated in the experiment. In addition to these persons, a number of other patients have participated occasionally.

\section{Results}

The first six months of supervised clinical experimentation have shown that the telethesis in its present state of development can be operated successfully by hospital personnel (occupational therapists) who are usually in charge of such patients. Unfortunately, due to the lack of personnel in the hospital, a substantial contribution in the actual training of the patients had to be made by personnel from the research laboratory, and the same patient had to work with different persons on various occasions. On the other hand, the close collaboration has been very useful in the evaluation and refinement of the training procedure, for the adaptation of the system to individual patients, and for the simultaneous improvement by the elaboration of the control procedure (such as the addition of the drinking mode).

The response of the occupational therapists was reserved at first, as they were concerned about the apparent complexity of the system. However, once they became familiar with the operating procedure and confronted with its potential, their response has become a positive one and active collaboration has been established.

The responses from the patients have been varied, ranging from a high interest and the desire to use the system, to its formal rejection. The best results have been obtained by patients $A$. T. and G. A., the only ones who have used the system for prolonged periods in the hospital. Both have completed the full training procedure described above and master all modes of operation. Both have used the head movement transducer with two degrees of freedom, the roller transducer and the bar-switch, both operated by gross arm movements. A. T. has been the first patient to proceed to the 'symbiotic' mode of operation, using his remaining arm movements in conjunction with the telemanipulator to complete various tasks in the most efficient way. Although both of these patients have functionally improved over the period covered and are able to perform some tasks with simple technical aids, the use of the telethesis has been accepted as a complement, significantly increasing their range of action and the number of tasks that they can perform independently.

The tasks performed are essentially those mentioned under the training procedure, and include drinking, eating and shaving, all requiring close contact with the head. Their initial apprehension has disappeared and these tasks are now executed with confidence. 
Subject C. M. (Fig. 2) a $\mathrm{C}_{3} / \mathrm{C}_{4}$ tetraplegic is the most severely disabled among the seven cited. He is a relatively 'old' tetraplegic, I. 5 year after the incident, and had been available for only a very short period during a ten day stay in the hospital. He has no voluntary function in his upper limbs and therefore had to use a control with three degrees of freedom on the head. He is the second person to use this configuration, after M. C., a $\mathrm{C}_{4}$ tetraplegic patient who used it in an extensive series of experiments in the laboratory. Whereas M. C. still had slight voluntary movement at his wrist to actuate the bar-switch, for C. M. the switch function had to be implemented by a sound signal, captured by a laryngophone placed over his throat.

While M. C. only gradually became motivated to use the telethesis when he discovered what he could do with it, C. M. was highly motivated from the beginning, working for $5 \frac{1}{4}$ hours during three intensive sessions. $\mathrm{He}$ is driving an electric wheelchair with chin control and he quickly learned to operate the system, using head movement control. Besides mastering all modes with the use of the $\mathrm{H}$-elements, he succeeded in controlling a lamp on top of a cupboard, to pour a drink and drink it, to fetch a telephone directory from a cupboard, and to perform a peg-in hole type task. For those among us who have worked with him it was a remarkable performance, unfortunately cut short by his discharge from the hospital.

Subject X. M. is at I 4 years the older one of the two children who have participated. He had a long-standing tetraplegia appearing at the age of three years, and has more arm function left than the other subjects. His participation served largely to test the system in younger subjects, and he has rapidly learned to operate the system with very good results, using it as a game, doing things he could not do. He has well accepted the system, coming for his sessions spontaneously on his free afternoon once a week, but the experimentation has been interrupted by a medical illness that requires a long period of convalescence.

G. E. at 5 years is the youngest of the subjects reported. The system has been presented to him as a game, partially operated by the experimenter and partially by himself. The primary object of these experiments is to aid the development of G. E.'s spatial representation, underdeveloped because of his condition. He has shown a great interest in this 'game', requesting it spontaneously to the surprise of the attending personnel.

In spite of good cooperation and a real interest in the telethesis, the results in patient $\mathrm{F}$. S. have been disappointing, due to long interruptions between sessions because of medical reasons, becoming easily fatigued, also from problems in maintaining a stable posture when seated, and because he has poor head movements. Although his condition had improved by the last session, his discharge from the hospital has interrupted the experiment.

Subjects G. Y. and J. S. have both refused prolonged experimentation for the following reasons:

G. Y.: 'I want to go home as soon as possible, I need my time for physical reeducation and I don't want to lose time in experimenting with a system that will not be available to me in my home'.

J. S.: In spite of the fact that he was seduced by the possibilities offered by the system when he tried it, he had a period of severe depression and rejected further experimentation: 'My immediate problems are not solved by the telethesis, it does not solve the problems of personal hygiene, of clapping when I need to cough, it will not solve my familial, financial and professional problems, and anyway, I do not see who would finance such a system for me'. 


\section{Discussion}

The rejections by J. S. and G. Y. exemplify some of the problems encountered in trying out novel approaches in a clinical environment with recent tetraplegic patients. The limited time that these patients can remain seated during the day, their varying physical and psychological states, and the interference with other therapeutic programmes pose a problem of availability, varying conditions, and scheduling of the experiments, that have been encountered with all subjects. This imposes a very flexible and personalised approach to each patient, interfering to some degree with a systematic standardised evaluation.

As a positive aspect it may be noted that in spite of these problems good acceptance has been obtained by a number of patients, that two of them have continued for prolonged periods of time and have achieved a very satisfactory performance. A very positive result is seen in the responses of the two most severely disabled persons, one studied in the laboratory and one in hospital, each using complete control by head movements. The initial rejection, but subsequent acceptance as performance increased in the first patient also indicates that a significant functional gain can be obtained. Since the relative gain in autonomy is greatest for those most disabled, constituting the primary aim for the telethesis, it should come as no surprise that they were the ones who showed most interest.

The experiments have also indicated that tetraplegic patients at lower neurological levels, who still have some arm function left, can profit from the possibility offered both to widen their range of action and to increase their functional possibilities in a 'symbiotic' type of operation with the external tool. Just how much gain can be obtained will require to be studied by a more elaborate evaluation.

Much experience has been gained from these experiments and from those in the laboratory, both with disabled and in normal subjects. The differences between subjects are not so much related to their handicap, but to their effectiveness in terms of mental spatial representation. It has been noted that the ease in learning is more related to the manual dexterity required in their (previous) profession than to intellectual skills.

The problems encountered with subject F. S., and the fact that others, and in particular bedridden patients, have not yet been able to participate indicates the need to pursue the studies on control transducers and associated procedures. In addition, procedures have to be developed to assure the user about independent access to the system and to regain control when the safety system trips following an operating error (excessive effort). Furthermore, the procedures developed should have an interest in rehabilitation beyond the control of a telethesis, and their application for the control of other technical aids, including wheelchair control and access to personal computers, is under study. The long-range goal is to develop a modular system of compatible units both to assist mobility and access to work activities, including manipulation.

\section{Conclusion}

The first experiments of the use of a telethesis by tetraplegic patients have shown the feasibility of using a remote telemanipulator to improve their function. The indications for its use should be studied in a larger group of patients, including not only those who are tetraplegic at different levels 
and from different aetiologies, but also certain patients with myopathy, cerebral palsy, rheumatic disorders, bilateral amputations, etc.

A cost-effective analysis should evaluate the socio-economic aspects of the use of such a system, considering the overall gain that can be obtained, including increased independence, reduced need for human help, professional implications, and improved quality of life; against the long term costs of its use. Further technological efforts must be made to reduce the complexity of the prototype system and reduce its cost. Finally, the 'spinoffs' for other applications should be exploited for the improvement of technical aids for the handicapped.

\section{RÉSUMÉ}

Dans le cadre du Projet Pilote Spartacus un prototype de téléthèse a été réalisé, un télémanipulateur pour des tétraplégiques de hauts niveaux lésionnels et des patients présentant des pathologies similaires.

Le système a une structure de commande modulaire, aussi bien dans le choix des capteurs que des programmes du microprocesseur assurant une liaison ergonomique avec l'utilisateur. Une procédure d'apprentissage a été mise au point et a été testée au laboratoire et à l'hopital.

Six tétraplégiques ont utilisé le système au laboratoire et sept à l'hopital. Ici nous rapportons les observations des six premiers mois d'expérimentation clinique receuillies sur sept sujets dans le service d'ergothérapie. La téléthèse a été bien acceptée par quatre sujets, dont deux l'ont utilisés pendant des périodes importantes. Pour un cas une adaptation satisfaisante n'a pas pu être réalisée avant le départ de l'hopital et dans deux cas l'utilisation de l'appareil a été rejetée, principalement pour des raisons psychologiques.

\section{ZUSAMMENFASSUNG}

Im Rahmen des französischen 'Spartakus' Projektes ist ein Prototyp 'Telethese', ein Telemanipulator für Tetraplegiker hohen Niveaus und anderen Schwerbehinderten, entwickelt worden. Das System hat eine modulare Steurungsstruktur, sowie in der Wahl der Aufnehmer als auch in der Programmierung des Mikroprozessors die die ergonomische Verbindung herstellt zwischen dem Behinderten und der Telethese. Eine speziale Trainungsprozedur ist entwikkelt worden und ist im Labor und in der Klinik getestet worden.

Sechs Tetraplegiker haben das System im Labor und sieben in der Klinik angewendet. Hier geben wir die Erfahrungen der ersten sechsmonatigen Experimente in der Ergotherapieabteilung mit den sieben Patienten wieder. Vier Patienten haben die Telethese gut akzeptiert, von denen zwei Personen sie für längere Zeit angewand haben. Bei dem Fall eines Patientens haben wir keine gute Anpassung machen können vor seinen Weggang. Zwei Patienten haben sich hauptsächlich aus Psychologischen Gründen geweigert das System länger anzuwenden.

\section{REFERENCES}

Durand, J., Bourlioux-Gavardin, M. \& Pannier, S. (1978). Résultats préliminaires d'une enquête nationale sur les tétraplégiques. Annales Méd. Phys., 21, 312-325.

Gaillard, J. P., Guittet, J., Kwee, H. H. \& Quetin, N. (I979). La téléthèse Spartacus: Bilan de $\mathrm{I} 7$ heures d'experimentation avec un tétraplégique de niveau $\mathrm{C}_{5}$. Proc. Second European Para-medical symposium on spinal cord injuries, Lyon, France, pp. F I-F55.

Guittet, J. KweE, H. H., Quetin, N. \& Yclon, J. (1979). The Spartacus telethesis: manipulator control studies. Bull. Prosth. Res., BPR 10-32, 69-105.

KweE, H. H. \& Pannier, S. (I98I). Medical robot for quadriplegics. Int. Robotics Workshop, Stanford Univ., Palo Alto.

LeIfER, L. (198I). Rehabilitative robots. Robotics Age, 3/3, 4-I 5.

VERTUT, J. (I978). La téléthèse Spartacus: conception mécanique du manipulateur MAT I. Proc. First Intern. Conf. on Telemanipulators for the Physically Handicapped, Rocquencourt, France.

WhITNEY, D. E. (I969). Resolved motion rate control of manipulators and human prostheses. IEEE Trans. on Man Machine Systems, MMS-Io, 47-53. 